\title{
15
}

\section{Teaching Business by Doing Business: An Interdisciplinary Faculty-Friendly Approach}

\author{
Larry K. Michaelsen, Mary McCord \\ Central Missouri State University
}

This chapter describes the implementation of an interdisciplinary undergraduate curricular innovation in two different university settings. The Integrative Business Experience (IBE) requires students to enroll concurrently in three required core business courses and a practicum course in which they develop and operate a startup business (based on a real-money loan of up to $\$ 5,000$ ) and carry out a hands-on community service project. This chapter also reports outcomes for students (including data from an assessment), examines the variables that minimize the difficulty of achieving cross-disciplinary integration in IBE, and suggests keys to enabling faculty-friendly integrative course designs in other settings.

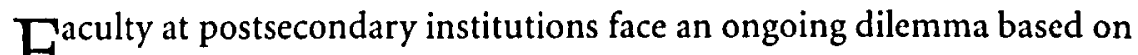
Tthe fact that academia is organized around discipline-based academic courses and departments while "Simply put: life is interdisciplinary" (DeZure, 1999, p. 1). On the one hand, faculty are trained within disciplines and, as a result, are seldom academically equipped to teach interdisciplinary courses unless they engage in and incur the costs that typically accompany any form of team-teaching. These include the additional time required for jointly developing plans for both dealing with the course content and evaluating student performance (Eby, 2001) and adjusting to student needs as the course unfolds (Harris \& Harvey, 2000). In addition, many members of 
teaching teams experience emotional costs that stem from learning to accommodate differences in each others' personalities (Robinson \& Schaible, 1995; Vogler \& Long, 2003) and teaching methods (Eby, 2001). On the other hand, studies report that interdisciplinary courses, teaching teams, or both produce a wide variety of benefits including revitalizing course material (Robinson \& Schaible, 1995), creating new styles of teaching (Inch \& McVarish, 2003), giving students access to "experts" (Ware \& Gardner, 1978) whose input promotes understanding across disciplines (Bartlett, 2002), higher achievement, greater retention, improved interpersonal skills, and an increase in regard for positive interdependence (Johnson, Johnson, \& Smith, 1991).

Although interdisciplinary learning initiatives are proliferating throughout higher education at an unprecedented rate (Creamer \& Lattuca, 2005; DeZure, 1999), it would appear that the costs of team-taught and/or interdisciplinary courses are still perceived to outweigh their benefits. However, based on our experience, just the opposite can be true. The purposes of this chapter are to 1) describe an undergraduate curricular innovation called the Integrative Business Experience (IBE) that has proven to be faculty-friendly even though it is both highly interdisciplinary and team-taught, and 2) review the evidence that has led us to conclude that the benefits of IBE have far outweighed the costs in two very different university settings.

\section{Background}

In most undergraduate business programs, students have four types of required coursework. During their freshman and sophomore years, they must complete a university core curriculum (a broad-based set of general education requirements) and a pre-business core (courses in economics, statistics, computers, business communications, and mathematics). In their junior year, they must complete a set of core courses that focus on four or five key business functions (finance, information systems, legal studies, management, and marketing). For the remainder of their junior year and in their senior year, students complete the coursework in their major and minor fields of study and conclude by taking a required capstone course.

The curricular innovation reported in this chapter involves a change in the way in which students completed their junior-level core business requirements. Traditionally, they had enrolled in four or five (depending on the university) stand-alone lecture-oriented courses. Starting in spring 1995 at the University of Oklahoma and in spring 2004 at Central Missouri State University, students have had the opportunity to choose a program 
called the Integrative Business Experience (IBE) (see Figure 15.1). This program, which was inspired by MG101 at Bucknell University (see Miller, 1991), links students' work in three core courses to an intensive hands-on experience (see Figure 15.2). Thus, in contrast to the traditional activities of listening, taking notes, and demonstrating competence by taking multiplechoice exams, IBE students have the opportunity to 1) practice using basic business concepts and analytical tools to solve a wide range of unstructured problems, 2) receive an integrated exposure to concepts from three core business disciplines, and 3) develop interpersonal and group interaction skills in a work-like setting. IBE students gain experience by creating and managing two significant enterprises-an actual startup company (funded by a real-money bank loan of up to $\$ 5,000$ ) and a hands-on community service project. They receive an integrated exposure to core business concepts as faculty deliver content instruction that is specifically sequenced to provide real-time conceptual support for managing students' business and service ventures. Students also have the opportunity to develop interpersonal and group problem-solving skills in both learning teams in the content courses (see Michaelsen, Knight, \& Fink, 2004) and through their IBE company activities.

FigURE 15.1

Traditional Versus IBE

Freshman/Sophomore

Junior Core

Post-Junior Core

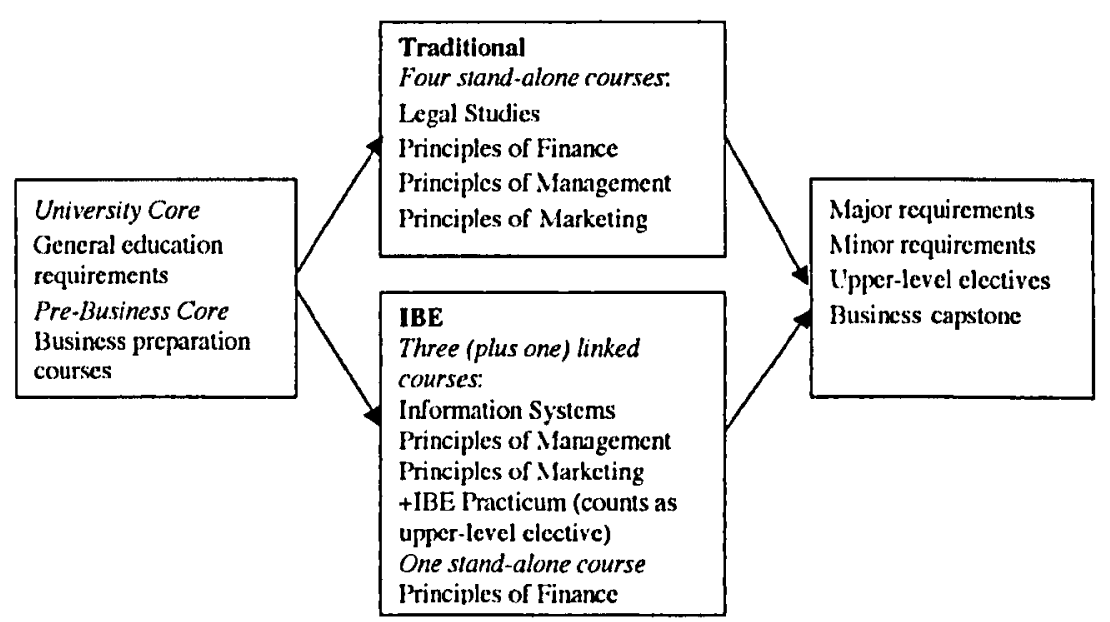


FIGURE 15.2

IBE Key Program Elements

Learning linked to experience. In one 16-week semester, students:

- Concurrently enroll in four courses-three required core business courses and an entrepreneurship/community service practicum

- Are responsible for mastering the content in the three required core business courses

- Are assigned to a permanent five- to seven-member learning team that is expected to complete projects and exams in all three core courses

- Are "employees" of a 20- to 35-member company ( 4 or 5 of the core course teams) that develops a business plan for:

$\sim$ A startup business venture

$\sim$ A hands-on community service project

- Obtain a real-money bank loan (up to $\$ 5,000$ ) to finance their startup business

- Generate enough income to pay back their loan and finance their service project

- Prepare and present a company annual report

Team-Based Learning to ensure:

- Content coverage

- Time for emphasis on concept applications

- Development of effective student teams

- Development of interpersonal/group problem-solving skills

\section{IBE Program Business and Service Outcomes}

In many ways, IBE has been a resounding success. For example, the financial and community service performance of IBE companies has surpassed our wildest expectations. A total of 1,474 students have participated in IBE between the 1995 spring semester and the 2003 spring semester at the University of Oklahoma, where the program was originally developed as the Integrated Business Core, and between the 2004 spring semester and the 2005 fall semester at Central Missouri State University. These students have formed and managed 53 remarkably successful companies. In total:

- IBE student businesses have received $\$ 171,926$ in loans (from a local - bank) and have generated total revenue of $\$ 1,175,374$ and total net profit of $\$ 671,789$. 
- More than 100 community service and/or voluntary nonprofit organizations have received $\$ 687,501$ in direct financial support from the efforts of IBE student businesses, and 22,352 hours of community service from IBE-organized activities.

\section{IBE's Impact on Students: Formal Assessment}

Both formal and informal data from students at the University of Oklahoma strongly suggest that the experience has had a profound positive effect on many aspects of their learning. The formal data were collected during class from 8 of the 10 sections of the Policy/Strategy capstone course (see Figure 15.1 shown earlier) in the final week of the 2001 spring semester. Students in these courses were all graduating seniors and, as a result, had completed their junior-core requirements 18 months to 2 years earlier. Further, since it was not a required track, we had the basis for a natural experiment on the impact of IBE.

We deliberately hid our intent to assess the impact of IBE in two ways. One was that there was no mention of IBE until a block of demographic questions at the very end of the questionnaire. The other was that the study was largely double blind in the sense that most of the instructors who administered the questionnaires used to collect the data for the study were unaware of its connection assessing the impact of IBE.

In all, 274 students (i.e., virtually all those who were present on the day the questionnaire was administered) completed the questionnaire. All but 23 of the respondents completed the question indicating whether or not they had participated in IBE. Thus, the responses of 251 students were usable. Of these, 201 had completed the junior core in the traditional track and 50 had participated in IBE.

The questionnaire used in the study contained 26 questions. The first set of questions asked students to rate (on a 1-5 Likert scale) the extent to which their experience in junior-level core courses (Legal Environment of Business; Principles of Finance, Information Systems, Management, and Marketing) and upper-division courses beyond the junior core had enabled them to develop skills, understanding, or both in seven specific areas (see Table 15.1).

The next two questions were open-ended so that students could express in their own words what they felt had been the single most beneficial aspect of their undergraduate business degree program, as well as the greatest disappointment in helping them develop the skills and understandings needed to be successful in their career. Students' responses on these questions were 
coded into one of nine categories that were developed from reading through and comparing students' write-in responses.

The final nine questions asked about different aspects of students' background "to help us learn if our program is 'working' better for some groups than for others." The question that asked students whether they had been in IBE was included in this set of background questions.

\section{s. Study Results}

The results from the seven questions related to students' experience in the junior-level core and in the upper-division courses beyond the junior-level core are shown in Table 15.1. In general, the scores indicate that IBE students had recalled their educational experience in both the junior-level core and in the upper-division courses beyond the junior-level core more favorably than students who had taken the same courses on a stand-alone basis. Ratings for students who had been in IBE were higher on all seven questions about both the junior-level core and the upper-division courses beyond the junior-level core. In addition, five of the seven differences between traditional and IBE students with respect to the junior-level core and four of the seven differences with respect to the upper-division courses beyond the junior-level core were significant beyond the .05 level.

Overall, the results show a consistent pattern suggesting that participation in IBE is uniformly associated with more positive ratings of a wide variety of important and positive educational outcomes. Even though students had completed their junior-level requirements some 18 months to 2 years before completing the questionnaire, the data support two important and positive outcomes that appear to be directly related to having participated in IBE. One is that IBE predisposes students to recall their junior-level core as having contributed more to their overall educational experience in a variety of ways. The other, and even more important, outcome is that even though both groups were asked to report on their experience in the same courses beyond the junior core (see Figure 15.1 shown earlier), IBE students reported that they had gained more from upper-division major and minor coursework than their peers who completed the junior-core requirements by taking four stand-alone courses.

\section{:. Students' Write-In Responses to the Open-Ended Questions}

The pattern of write-in responses of traditional students was very different than that of IBE students on all three open-ended questions. Students' responses to the first open-ended question ("What has been the single most 


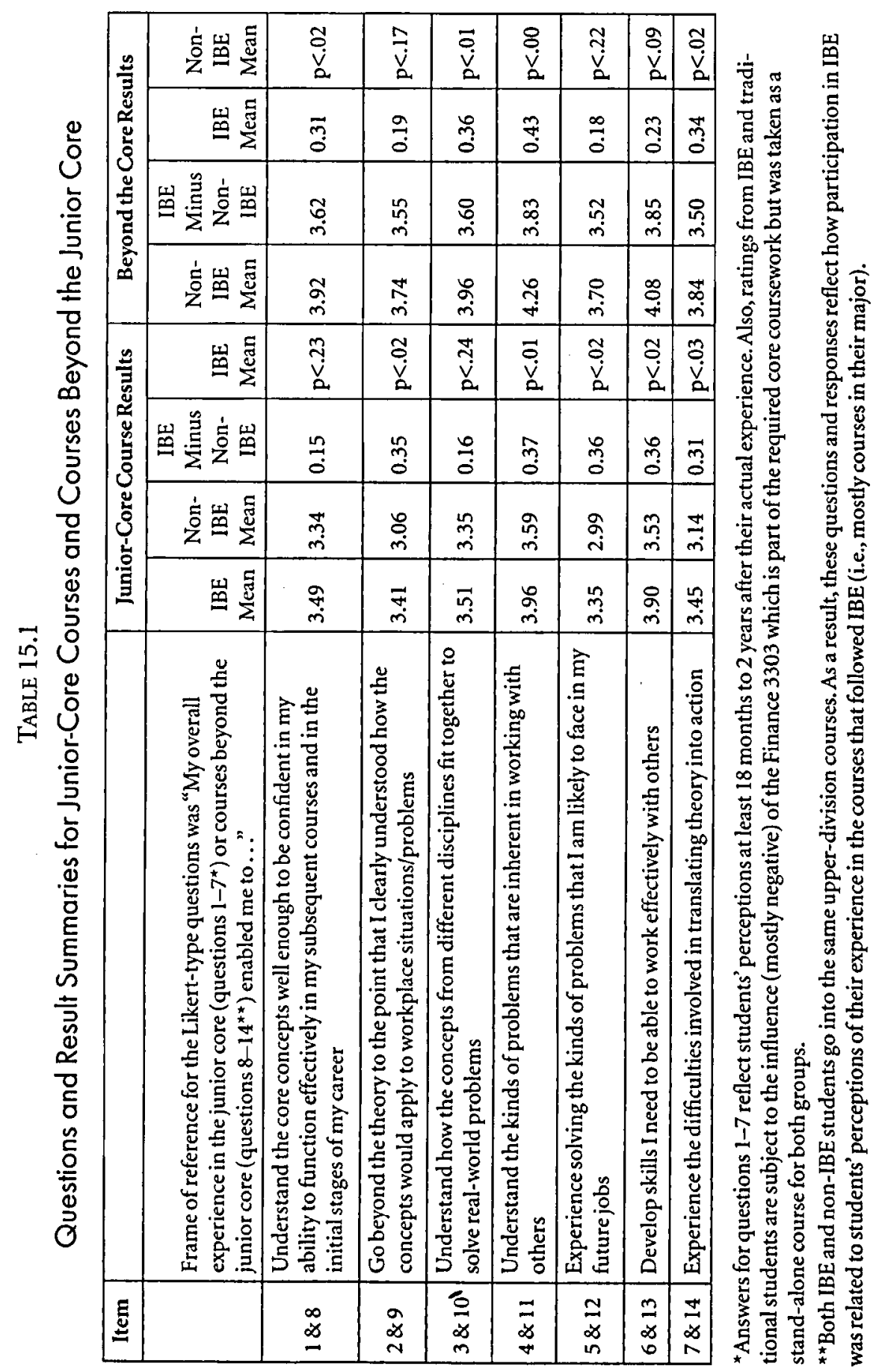


beneficial aspect of your undergraduate business degree program?") showed three differences that were quite striking (see Table 15.2). First, almost $31 \%$ of the students who had completed the traditional junior core either left the question blank or made some sort of a negative comment. By contrast, only $4 \%$ of the former IBE students left the question blank and none gave a negative comment. Second, only one student in the non-IBE group wrote a positive comment specific to the junior core (she commented on the positive influence of the Marketing Principles instructor in helping her to decide on a major), while $50 \%$ of the former IBE students specifically mentioned their participation in IBE as being the single most beneficial aspect of their undergraduate business degree program. Third, $10 \%$ of the students who completed the junior-core requirements by taking the four stand-alone courses identified "good teaching" (often citing one or more specific teachers by name) as the single most beneficial aspect of their undergraduate business program. By contrast, "good teaching" was not even mentioned by former IBE students.

TABLE 15.2

Most Beneficial Aspect of Students' Degree Program

\begin{tabular}{|r|r|r|r|l|}
\hline \multicolumn{2}{|c|}{ Non-IBE } & \multicolumn{2}{|c|}{ IBE } & \multicolumn{2}{|c|}{ Responses Coding Category } \\
\hline $\mathrm{n}$ & $\%$ & $\mathrm{n}$ & $\%$ & \\
\hline 49 & $24.4 \%$ & 2 & $4.0 \%$ & Left question blank \\
\hline 13 & $6.5 \%$ & & $0.0 \%$ & Gave negative (e.g.,"absolutely nothing," you must be kidding") \\
\hline 1 & $0.5 \%$ & 25 & $50.0 \%$ & Something specifically related to junior core and/or named IBE \\
\hline 31 & $15.4 \%$ & 7 & $14.0 \%$ & Group work/teamwork \\
\hline 52 & $25.9 \%$ & 11 & $22.0 \%$ & $\begin{array}{l}\text { Post-junior core (e.g. "field project," "working with cases," } \\
\text { "capstone") }\end{array}$ \\
\hline 20 & $10.0 \%$ & & $0.0 \%$ & Specific mention of one or more good teachers \\
\hline 10 & $5.0 \%$ & 2 & $4.0 \%$ & Extracurricular (e.g., leadership program, clubs, placement) \\
\hline 14 & $7.0 \%$ & 1 & $2.0 \%$ & $\begin{array}{l}\text { Concepts learned/skills gained (e.g., "business knowledge," } \\
\text { "computer skills") }\end{array}$ \\
\hline 11 & $5.5 \%$ & 2 & $4.0 \%$ & $\begin{array}{l}\text { Other (e.g., "friendships,"“learned how to learn," "gained } \\
\text { self-discipline") }\end{array}$ \\
\hline
\end{tabular}

Except for one common theme, students' write-in comments on the second open-ended question ("What aspect of your undergraduate program has been the greatest disappointment with respect to helping you develop the skills and understandings you will need in your chosen career?") were also 
quite different for traditional and IBE students. The only common theme was "bad teaching": more than $30 \%$ for both groups, with more than one-half of the complaints focusing on the junior-core courses (see Table 15.3).

TABLE 15.3

Students' Greatest Disappointment in Personal Outcomes From Degree Program

\begin{tabular}{|r|r|r|r|l|}
\hline \multicolumn{2}{|c|}{ Non-IBE } & \multicolumn{2}{|c|}{ IBE } & \multicolumn{1}{|c|}{ Responses Coding Category } \\
\hline $\mathrm{n}$ & \multicolumn{1}{|c|}{$\%$} & $\mathrm{n}$ & \multicolumn{1}{c|}{$\%$} & \\
\hline 47 & $23.4 \%$ & 4 & $8.0 \%$ & Left question blank \\
\hline 3 & $1.5 \%$ & & $0.0 \%$ & Undifferentiated negative (e.g., "everything," "too many to list") \\
\hline 14 & $7.0 \%$ & 8 & $16.0 \%$ & Bad teaching in and/or philosophy of Finance 3303 \\
\hline 21 & $10.4 \%$ & 1 & $2.0 \%$ & Bad teaching in and/or philosophy of other junior core \\
\hline 26 & $12.9 \%$ & 7 & $14.0 \%$ & Bad teaching (post-junior core and/or general) \\
\hline 7 & $3.5 \%$ & 1 & $2.0 \%$ & Group work/teamwork in post-junior core \\
\hline 33 & $16.4 \%$ & 15 & $30.0 \%$ & Toolittle "real-world" focus (more experience and/or assignments) \\
\hline 17 & $8.5 \%$ & 3 & $6.0 \%$ & Irrelevant coursework \\
\hline 33 & $16.4 \%$ & 11 & $22.0 \%$ & $\begin{array}{l}\text { Other (e.g., "enrollment," "program inadequacies," "outdated } \\
\text { courses") }\end{array}$ \\
\hline
\end{tabular}

Again, the differences between traditional and IBE students seem to be concentrated in three areas. First, a much higher proportion of traditional students either left the question blank or wrote in an undifferentiated negative than was the case for IBE students. Second, although both groups voiced concerns about the teaching and or philosophy of the junior-core courses, the focus of their comments was quite different. Both groups had concerns about the Principles of Finance course, but a much higher percentage of IBE students listed it as their greatest disappointment than was the case for traditional students ( $16 \%$ versus $7 \%$ ). On the other hand, $10.4 \%$ of the traditional students wrote in comments about one or more of the stand-alone juniorcore courses as compared to the one student $(2 \%)$ who was clearly disappointed in the teaching in IBE ("The IBE teachers didn't teach"). Finally, although students who had participated in IBE reported having had a higher degree of "real-world" focus in both their junior core and in their subsequent courses (see items 7 and 14 in Table 15d shown earlier), a much higher percentage wrote that "too little real-world focus" was their greatest disappointment than was the case for traditional students ( $30 \%$ versus $16.4 \%$ ). 


\section{Informal Assessment: Comments From Students' Program Portfolios}

The second school involved in the study is Central Missouri State University (CMSU), a mid-size, regional, teaching-oriented school, with a population of 16,000 . Since the IBE program had only been in operation at CMSU for three semesters when this chapter was written, we had no opportunity to conduct a formal assessment of its impact like the one at the University of Oklahoma. However, comments from a program portfolio (graded pass-fail) that students are required to create for prospective employers provide persuasive evidence supporting the same kinds of outcomes that occurred at the University of Oklahoma. Some of their comments are as follows:

I feel that I learned more and got more experience in the IBE class than I have in any other school activity. I feel that I have a better understanding of myself and of other people. I am more willing to work in groups to accomplish goals. I would recommend taking the IBE class even if I wasn't a business major.

Almost all of my learning experiences came from actually doing something or relating the topic to something that I already had knowledge of. For example, I can study for a test and make an "A." This does not mean that I learned the material, though; I will most likely forget it within the week. However, if I can physically do an action, it is easier to remember.

I always thought that people would only help me if they could get some sort of benefit from it. After participating in my company, I have realized that is simply not true. Most people are willing to help with anything you could need. Bcing part of a non-profit organization really opened my eyes to this.

I have learned one must take the good with the bad, the fun with the work, and at times, just complete frustration. The ability to manage all these feelings and moods is what makes a student a leader in a class and potentially a leader in the business world.

This experience has not only taught me the course material, or how to start and run a business, but also it has taught me a lot about myself. I , am a very hard worker and always strive for success. I have also learned that I care about other people and their own opinions. I have also discovered that I learn best from trial and error and hands-on experience. 
Overall the IBE experience has been one of the best I've had since I have been in college. Just learning about the key factors of running a business and growing along the side of your peer was an experience within itself. I have earned a greater respect for those who have tried, but sometimes have failed and also those peers that have now become my friends.

Being in IBE was a one of a kind experience and I would recommend it to every business major. I learned things about myself, interacting with others, and had my first hands on business experience.

I've learned that I tend to take control on my side of things and don't let others help me. Had I gotten someone to help me, maybe things could have gone faster and better. My interaction with others has changed greatly over the course of the semester.

I was complimented on my presentation, but learned bankers are much more pessimistic than optimistic. The numbers I showed them were for a "best case" scenario, and they expanded my knowledge for the future by explaining the reasons to use a "worst case" instead...

The service project was a great experience raising money for such a good organization. It has taught me important areas such as ethics, communication, and working with others as a member of a team.

I have learned a lot about myself from this class. I have learned now that people need incentive or need a drive to succeed. For me a drive is money and will always be money, but in this class we didn't make a profit, so we couldn't pay our employees with money. We had to energize our members to sell without incentives.

IBE has opened a gateway into a different learning style for me and it has also helped in the learning aspects of my other courses that I am taking and will take. If I had to go back and choose to do IBE, I would make the same choice and not change a thing.

Many of the comments indicate that students were learning a great deal about themselves as well as developing the knowledge of business concepts and work-related skills. IBE is often a student's first opportunity to assess their abilities in a setting that approximates the kinds of situations they will face when they graduate and enter the workforce. 


\section{Discussion}

Data from the formal study at the University of Oklahoma clearly support two very important conclusions with respect to the impact of IBE. First, students who participated in IBE perceived that the knowledge and skills they had gained from their junior-core courses were greater than was the case for non-IBE students. Second, even though they were enrolled in exactly the same post-core courses as the students who took the four stand-alone juniorcore courses, IBE students appear to have gained more from and had a more positive experience in their subsequent courses. They were more confident in their understanding of course concepts, how concepts from different disciplines fit together, the problems inherent in working with others, and how to translate theory into action. In addition, the student comments from CMSU strongly suggest that the IBE experience enables students to learn much about themselves as well.

Although any conclusions about students' attitudes require a degree of inference, data from literally every question in the entire questionnaire and from each of the student comments suggest that participation in IBE has a strong and lasting positive impact on students' attitudes. For example, one clear indicator is that IBE students' scores on all 14 questions that asked them to rate the understandings and skills they had gained from the junior core and from their subsequent coursework (see Table 15.1 shown earlier) were higher than the traditional group.

In our judgment, some of the data from the open-ended questions provide less direct but even more powerful evidence of IBE's positive impact on students' attitudes. For example, one general indicator is simply that a much higher number of non-IBE students were unwilling to put forth the effort to answer the open-ended questions than were former IBE students (see Tables 15.2 and 15.3 shown carlier). Another indicator is that, as a group, the students who were in the traditional junior core seem to have taken a far more negative slant in answering the open-ended questions. For example, when asked about the beneficial aspect of their undergraduate business degree program, six times as many in that group failed to provide any answer, and another $6.5 \%$ wrote in a negative comment, compared to $0 \%$ for the IBE group (see Tables 15.2 and 15.3). Further, in contrast to the traditional group, none of the former IBE students wrote in an undifferentiated negative on the question asking for students' greatest disappointment.

-Probably the greatest strength of the study was the fact that the data were collected in a setting that was temporally and contextually removed from the junior core. This allowed us to be quite confident that the responses were 
largely unbiased with respect to the issues we wanted to study. On the other hand, because IBE was not a required program, we had no way of knowing how much of the differences reported by traditional versus IBE students were due to self-selection bias. To some extent, however, our concerns in this area were reduced by two factors. First, the ability level of the two groups (measured by GPAs at the time they entered the junior core) was identical. Second, although we know that two types of students were overrepresented, the impact would seem to be offsetting. One overrepresented group was students who were in the JCPenney Leadership Program. These students were all in the upper tier with respect to their academic performance. The other overrepresented group consisted of students in three potentially at-risk categories who were encouraged by academic counselors to enroll in IBE. These were students who were unsure they really wanted to major in business, students who thought they wanted a business degree but were unable to decide on a major, and students who were "on contract" because they had low GPAs.

The other major weakness in the study was that it was, at best, an interim report because the real test of the impact of IBE had not yet occurred. Even though the graduating seniors who were in IBE reported having gained more from both their junior-core and their subsequent courses, the real test will come when they actually go to work. Unfortunately, that study will have to come later.

\section{Impact on Faculty}

\section{Benefits}

The greatest benefit for faculty is a direct result of students' reactions to IBE. Teaching in a setting where the vast majority of students are growing both professionally and personally is truly rewarding. In many ways, it is a dream that just keeps coming true-sometimes in spite of the fact that, particularly in the early stages of the program, we were still trying to figure out how to take advantage of the powerful "teaching moments" that regularly and automatically occur as students are trying develop and implement their business and service ventures. Other benefits are less obvious but no less real. One is an ongoing opportunity to enrich students' understanding of the material being taught as a natural consequence of seeing it in a context that is both applied and automatically linked to ideas from other disciplines.

Another benefit is that IBE faculty have a great deal of flexibility in managing their teaching schedule. The core courses are scheduled for three consecutive hours on a Monday/Wednesday/Friday schedule, followed by an hour for 
the practicum during which students generally meet on their own to do company business. Prior to the start of the semester, we create a master calendar showing which blocks of time each faculty member will be meeting with students and can easily adjust the schedule to work around everything from lab availability or academic conferences to special family events that we would be hesitant to miss a class to attend. Further, when emergencies arise (e.g., illness), we can almost seamlessly adjust to meet our teaching needs without creating problems for either students or our own overall class schedule.

\section{-Costs}

The major faculty cost associated with IBE is remarkably small and is primarily limited to the additional effort required in two areas during the first semester of teaching the course. One is that instead of following a sequence in their textbook, each instructor is required to resequence their own topics with the idea of covering topics "just-in-time" in relation to students' needs as they formulate and operate their businesses. The other is the cost of developing team assignments that produce information that can be used to meet company needs. For example, instead of having teams do market analysis for an existing business, the marketing instructors need to reframe the assignment so that teams are doing an analysis of a potential business for the students' own startup company. Another cost has been that the faculty team meets weekly (usually for about one-half hour) with a group consisting of a student advisor (who is paid a modest stipend) from each company to brief the faculty on students' progress, issues, and concerns. All these costs are, however, offset by the fact that the faculty effort required to supervise the practicum is less than would be required for a normal course in which they would be organizing and carrying out a teaching plan.

\section{Conclusion}

The overwhelmingly positive impact on students combined with the fact that the approach is faculty-friendly appears to be so unusual that it naturally leads to two questions: Why does it work so well? What can we learn from this example that might enable similar win-win outcomes in other situations?

In part, our answer to the first question is no different than the advice offered a number of years ago by Ward (1988), who maintained that the key is using projects in which students solve real-world problems, and by Pappas, Kiefer, and Levstik (1990), who argue that interdisciplinary/cross-curricular teaching should be organized around activities that promote and support the 
active construction of meaning for students. We have simply implemented those two ideas in a business school setting. There is nothing more "real world" for business students than getting a real-money loan and starting a business, and there is no better opportunity for constructing the meaning of core business concepts than trying to use them to run their own business. This, in fact, is the simple explanation of why IBE is so faculty-friendly. The experience is so compelling that as long as faculty have individually exposed students to the relevant concepts from the courses in a sequence that links them to the business and/or service activities of the practicum, integration of the concepts from different disciplines almost automatically occurs in students' heads. There is simply little or no need for the extremely difficult and time-consuming work that typically threatens the sustainability of interdisciplinary teaching efforts-close coordination of concepts by faculty members from different disciplines.

With respect to the second question, we strongly believe that our positive experience with interdisciplinary teaching can be replicated in other settings by following two key guidelines. The most important is building the interdisciplinary teaching effort around a situation or problem that is challenging, is focused on doing, and is truly "real life" for the students. The other is finding a group of faculty who clearly understand how their discipline relates to the situation or problem and who are willing to use a teaching approach that actively involves students in the construction of meaning (Michaelsen et al., 2004; Savin-Baden \& Major, 2004).

\section{References}

Bartlett, T. (2002, May 10). Students become curricular guinea pigs. The Chronicle of Higher Education, p. A12.

Creamer, E. G., \& Lattuca, L. R. (Eds.). (2005). New directions for teaching and learning: No. 102. Advancing faculty learning through interdisciplinary collaboration. San Francisco, CA: Jossey-Bass.

DeZure, D. (1999). Interdisciplinary teaching and learning. Retrieved June 19, 2006, from the College of Charleston, Center for Effective Teaching and Learning web site: www.cofc.edu/ cetl/Essays/InterdisciplinaryTeaching\&Learning.htm

Eby, K. K. (2001, Summer/Fall). Teaching and learning from an interdisciplinary perspective. Peer Review, 3-4(4-1), 28-31. 
Harris, C., \& Harvey, A. N. C. (2000). Team teaching in adult higher education classrooms: Toward collaborative knowledge construction. In M-J. Eisen \& E. J. Tisdell (Eds.), New directions for adult and continuing education: No. 87. Team teaching and learning in adult education (pp. 25-32). San Francisco, CA: Jossey-Bass.

Inch, S., \& McVarish, J. (2003, February). Across the divide: Reflecting on university collaboration. Reflective Practice, 4(1), 3-10.

Johnson, D. W., Johnson, R. T., \& Smith, K. A. (1991). Cooperative learning: Increasing college faculty instructional productivity. San Francisco, CA: Jossey-Bass.

Michaelsen, L. K., Knight, A. B. \& Fink, L. D. (Eds.). (2004). Team-based learning: A transformative use of small groups in college teaching. Sterling, VA: Stylus.

Miller, J. A. (1991, May). Experiencing management: A comprehensive, "hands-on" model for the introductory undergraduate management course. Journal of Management Education, 15(2), 151-169.

Pappas, C. C., Kiefer, B. Z., \& Levstik, L. S. (1990). An integrated language perspective in the clementary school: Theory into action. New York, NY: Longman.

Robinson, B., \& Schaible, R. M. (1995, Spring). Collaborative teaching: Reaping the benefits. College Teaching, 43(2), 57-60.

Savin-Baden, M., \& Major, C. H. (2004). Foundations of problem-based learning. London, England: Open University Press.

Vogler, K. E., \& Long, E. (2003, September). Team teaching two sections of the same undergraduate course: A case study. College Teacling, 51(4), 122-126.

Ward, G. (1988). I've got a project on ... Portsmouth, NH: Heinemann.

Ware, M. E., \& Gardner, L. E. (1978, October). Team teaching introductory psychology as pedagogy and for faculty development. Teaching of Psychology, 5(3), $127-130$. 